ORIGINAL ARTICLE

\title{
Mechanical and psychosocial factors predict new onset shoulder pain: a prospective cohort study of newly employed workers
}

\author{
E F Harkness, G J Macfarlane, E S Nahit, A J Silman, J McBeth
}

Occup Environ Med 2003;60:850-857

See end of article for authors' affiliations

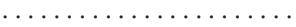

Correspondence to: Ms E F Harkness, ARC Epidemiology Unit, Medical School, University of Manchester, Oxford Road, Manchester M13 9PT, UK; moeyjefh@ fs 1 .ser.man.ac.uk

Accepted

17 November 2002

\begin{abstract}
Aim: To test the hypothesis that work related mechanical and psychosocial factors predict new onset shoulder pain in newly employed workers.

Methods: Two year prospective study of newly employed workers from 12 diverse occupational settings. At baseline, 1081 subjects provided information on work related mechanical and psychosocial risk factors, and current pain status.

Results: In all, $803(74 \%)$ subjects were free from shoulder pain at baseline. Of those, 638 (79\%) responded at 12 months and $476(88 \%)$ at 24 months. New onset shoulder pain was reported by 93 $(15 \%)$ and $73(15 \%)$ subjects respectively. An increased risk of symptom onset was found in subjects reporting mechanical exposures involving heavy weights including lifting with one or two hands, carrying on one shoulder, lifting at or above shoulder level, and pushing or pulling. Working with hands above shoulder level was also predictive of new onset shoulder pain. Of the psychosocial factors examined, the strongest predictor was monotonous work. Those individuals with any other previous pain also had an increased risk of new onset shoulder pain at follow up. In multivariate analysis, lifting heavy weights with one or two hands, pushing or pulling heavy weights, working with hands above shoulder level, and monotonous work were independently associated with new onset shoulder pain.

Conclusions: This study supports the hypothesised relation between mechanical risk factors and shoulder pain. In general, work related psychosocial factors were modestly associated with new onset shoulder pain. However, monotonous work was a strong risk factor for new onset shoulder pain.
\end{abstract}

$\mathrm{P}$ revious studies have suggested that there is a causal relation between mechanical factors, such as work load, posture, and repetitive movements, and an increased risk of new onset shoulder pain..$^{1-3}$ It has also been hypothesised that various organisational and social factors of the working environment, may lead to increased stress in individuals, which in turn may be related to a variety of adverse health outcomes. ${ }^{4}$ In particular, individuals who have little control, high workplace demands, and low social support from colleagues or supervisors are thought to be at increased risk of developing poor health outcomes. ${ }^{4}$ Such psychosocial factors have also been associated with shoulder pain; however, these findings have not been consistent. ${ }^{235}$

The inconsistency in reported results may arise for a number of reasons. Previous studies may be biased as a result of the "healthy worker effect". Studies conducted within a well established workforce may comprise those individuals least likely to have an adverse outcome from exposure. This is due to workers who become ill changing their job or job conditions, thus leaving a relatively healthy workforce. The healthy worker effect may lead to an underestimate of the risk of shoulder pain since exposures and outcomes will be under-represented by such a cohort. In addition, studies have tended to be cross sectional and are subject to recall bias. Longitudinal studies are therefore required in order to determine the temporal relation between exposure and outcome. ${ }^{3}$

The current study was designed as a prospective cohort study to examine mechanical and psychosocial risk factors for new onset shoulder pain in a range of occupational groups. In order to minimise the healthy worker effect individuals who were new to the workforce were recruited. The main aim of the present study was to test the hypothesis that mechanical and psychosocial factors predict the new onset of shoulder pain. To address this hypothesis we examined the association between risk factors in five specific domains (mechanical load, posture and repetitive movements, psychosocial factors, working conditions, and other pain) and the new onset of shoulder pain. We then evaluated the relative contribution of these domain specific exposures in symptom onset.

\section{METHODS}

\section{Design}

The design was a prospective cohort study of newly employed workers. At baseline subjects completed a questionnaire which assessed current pain status and measured various aspects of work related mechanical and psychosocial risk factors. Subjects free from shoulder pain were identified and followed up at 12 and 24 months. Those reporting new onset shoulder pain were identified (fig 1).

\section{Subjects}

Subjects were recruited from 12 diverse occupational groups. Occupations were chosen so that a large proportion of subjects would be taking up full time employment for the first time $(46 \%)$. Occupations previously identified in the literature as having high rates of musculoskeletal disorders and thought to have a comparatively stable workforce were included. Subjects were selected from three sources: (1) sites recently opened and employing a new work force; for example, a supermarket and postal distribution centre; (2) service or established organisations recruiting sizeable numbers of new employees; for example, police and fire service; and (3) final year students completing vocational courses; for example, dentistry and nursing students. The 


\section{Main messages}

- Many previous studies of symptom onset have been conducted in well established work forces and may be influenced by the healthy worker effect.

- Mechanical work related risk factors were strong predictors of new onset shoulder pain.

- The contribution of work related psychosocial factors to symptom onset was modest; however, monotonous work was an important predictor of new onset shoulder pain.

sources for recruitment are described elsewhere, ${ }^{6}$ but details are briefly given in the Appendix.

\section{Baseline exposures}

Each subject completed a 23 page questionnaire at baseline which, in addition to demographic information, gathered detailed information on five individual domains of possible risk factors for new onset shoulder pain.

- Manual handling activities. The questions relating to work related manual handling activities were based on previous research which had validated a self completion instrument designed to measure the frequency, duration, and weights of work related mechanical tasks performed. ${ }^{7}$ Specifically, questions asked about carrying weights on one shoulder, lifting weights with one or two hands, pushing or pulling weights, and lifting weights at or above shoulder level during the past working day. Subjects were asked to estimate (with the use of a guide) the weights they lifted and the duration of each task in minutes. The weight guide was a visual analogue scale, along which several household and work related items were placed, with weights given in pounds and kilograms.

- Postures and repetitive movements. The questions relating to work related postures and repetitive movements were again based on a previously validated instrument. ${ }^{7}$ Individuals were asked about several postures and repetitive movements during the past working day (driving, stretching below knee level, working with hands at or above shoulder level, and repetitive movements of the arms or wrists) and how much of their time was spent in each position.

- Work related psychosocial factors. Questions examining work related psychosocial factors were based on the model of Karasek and colleagues, ${ }^{4}$ which has previously been used to examine psychosocial factors in a number of studies of musculoskeletal pain, including low back ${ }^{89}$ and forearm pain. ${ }^{10}$ Individuals were asked about the following items in relation to their current job: job satisfaction, whether they felt their work was monotonous or boring, work pace, stress/worry, control over work, ability to learn new things, and support from work colleagues and supervisors. In addition the 12 item General Health Questionnaire (GHQ) was included as a measure of psychological distress. ${ }^{11}$

- Working conditions. Subjects were asked whether they worked in hot, cold, or damp conditions during their past working day and, if so, for how long.

- Current pain status. To assess pain status subjects were asked, "Thinking back over the past month, have you had any ache or pain which lasted for one day or longer?" If so, subjects were asked to indicate the site of this pain on a line drawing of the body. Shoulder pain was defined as

\section{Policy implications}

- Load bearing is unavoidable in many occupations and psychosocial interventions may be less difficult to implement.

- Targeting the perception of monotonous work may be one possible avenue for intervention.

pain in the shoulder complex lasting for one day or longer in the past month (fig 2).

At baseline 1186 individuals received a questionnaire, which was completed by 1081 subjects. The questionnaire was distributed and completed during organised sessions in the workplace. A few individuals who were absent on the day of these sessions received a postal questionnaire with up to two reminders sent to non-responders.

\section{Follow up}

Those subjects identified at baseline as free from shoulder pain were eligible for follow up. Follow up questionnaires were mailed to subjects at 12 and 24 months, with up to two reminders sent to non-responders. Pain status was again assessed using a body manikin. In addition a pre-shaded manikin was used to enquire about shoulder pain lasting at least 24 hours in the past month (fig 2). Individuals were also asked to record any changes in their job or job related activities due to aches or pains. New onset shoulder pain was defined in a similar manner to baseline.

\section{Analysis}

At baseline a cohort free from shoulder pain was identified. The associations between ( 1 ) exposures at baseline and new

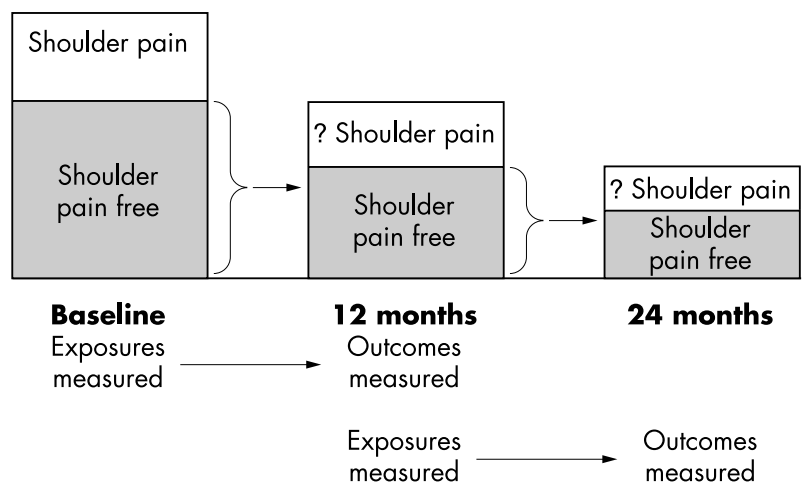

Figure 1 New onset of shoulder pain from baseline to follow up.
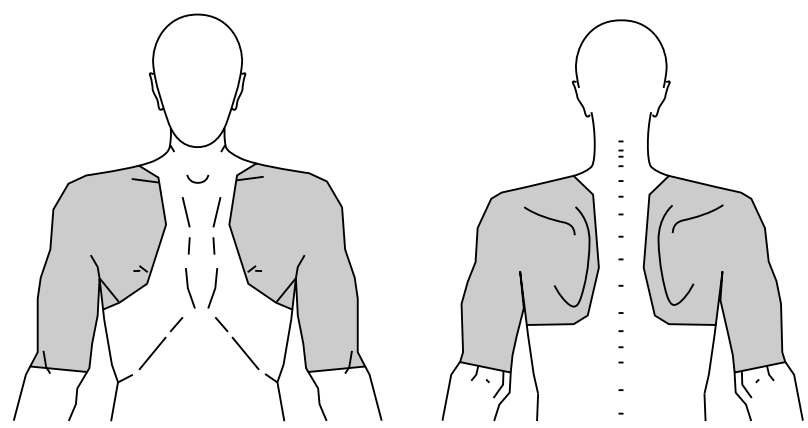

Figure 2 Manikin used to record shoulder pain. 
onset shoulder pain at 12 months and (2) exposures at 12 months and new onset of shoulder pain at 24 months (fig 1) were examined.

For analysis of the mechanical exposures, subjects who did not perform a manual handling activity were categorised as the referent group. Subjects who performed these activities were dichotomised into two equal groups based on the distribution of the weights lifted. Similarly, subjects who did not report potentially harmful work related postures and repetitive movements were categorised as the referent group, with those who did divided into two equal groups based on the time spent in each position. Subjects scoring 0 on the GHQ formed the referent group with the remaining subjects being divided into three equal sized groups, based on the distribution of the scale score. All other exposure variables were dichotomised.

Because of the nature of the study design we had exposure and outcome data available at three time points. Time-series data can be analysed using generalised estimating equations (GEEs) ${ }^{12}$ which were employed in this study to determine predictors of new onset shoulder pain. GEEs take account of the within subject correlation measured at multiple time points. As a result, one summary estimate is given for the relation between predictors at baseline and outcome at 12 months and for predictors at 12 months and outcome at 24 months. Results are expressed as odds ratios (OR) with 95\% confidence intervals (95\% CI), adjusted for age, gender, and occupational group. The final model of the predictors of new onset shoulder pain was constructed as detailed below:

- Univariate associations, adjusted for age, gender, and occupational group, were assessed for each explanatory variable.

- To identify those factors which best predicted new onset shoulder pain within specific domains, multivariate models were constructed separately for each domain. Where two variables were strongly correlated with each other, the variable that had the strongest or most robust estimate from the univariate analysis was included in the domain specific model.

- To identify the smallest number of predictive factors, a final multivariate model was constructed by entering the predictor variables from the domain specific models. Variables were selected for entry if the domain specific association was statistically significant, the $O R \geqslant 1.5$, or the $\mathrm{OR} \leqslant 0.67$.

Each predictor variable in the final multivariate model was examined for interactions with other predictor variables and follow up period. Interactions were included in the final model if they were considered to be biologically plausible, and were statistically significant, or had an $O R \geqslant 1.5$ or $\mathrm{OR} \leqslant 0.67$, and contributed significantly to the final model.

All analyses were conducted using the statistical package STATA (version 7). ${ }^{13}$

\section{RESULTS}

\section{Prevalence of new onset shoulder pain}

Figure 3 shows the flow of participants from baseline recruitment through to the final follow up at 24 months. At baseline 260 individuals (24\%) reported shoulder pain. The remaining 803 individuals without missing information and free from shoulder pain were therefore eligible for follow up. Men comprised a larger proportion of the study cohort (65\% males versus $35 \%$ females); median age of those eligible for follow up was 23 years (interquartile range 20-27 years). The prevalence of new onset shoulder pain at 12 and 24 months was the same, with 15\% reporting symptoms at both follow up periods ( $\mathrm{n}=93$ and 73 respectively).
The prevalence rate of new onset shoulder pain did not differ by age and gender, but was found to vary by occupational group (table 1).

\section{Univariate associations}

Table 2 shows the univariate associations between mechanical risk factors and subsequent shoulder pain, adjusted for age, gender, and occupational group. All manual handling activities conferred an increased risk of shoulder pain, and those individuals who handled heavier weights had almost double or more than double the odds of developing new onset shoulder pain when compared to those who did not perform these activities. Subjects who also worked with their hands above shoulder level for 15 minutes were also at an increased risk of symptom onset (table 2).

Most of the work related psychosocial factors examined did not predict symptom onset. However a perception of one's work as monotonous or boring was strongly associated with new onset shoulder pain, with those subjects almost twice as likely to develop symptoms at follow up (table 3 ).

Of the other factors examined, hot, cold, and damp working conditions did not predict new shoulder pain at follow up (table 4). Those with any other previous pain had an increased odds of developing new onset shoulder pain at follow up (table 4).

\section{Final predictive model}

Lifting weights at or above shoulder level was excluded from the final model due to the inconsistency in the odds ratios by weight category in the domain specific model. In addition, this variable was strongly correlated with working with hands above shoulder level and with lifting weights with one or two hands.

Therefore those factors from the domain specific models meeting the inclusion criteria for the final multivariate model were: lifting weights with one or two hands, pushing or pulling heavy weights, working with hands above shoulder level, monotonous work, and other pain.

The final model, shown in table 5, shows that lifting weights with one or two hands, pushing or pulling heavy loads, working with hands at or above shoulder level, and monotonous work all carry independent risks for new onset shoulder pain. The prevalence of new onset shoulder pain was observed to increase by the number of these factors subjects were exposed to. The prevalence rate of new onset shoulder pain was $9 \%$ in those exposed to none of these factors, increasing to $13 \%, 18 \%, 31 \%$, and $33 \%$ in those exposed to one, two, three, or four factors respectively. In addition, the area under the receiver operator characteristic (ROC) curve was calculated as 0.67 , indicating that the model was good at predicting new onset shoulder pain.

\section{Participants and non-participants}

Overall response rates were high but varied according to occupational group (table 1). Of those individuals free from shoulder pain at baseline, $79 \%$ participated in the 12 month follow up, and of those free from shoulder pain at 12 months, $88 \%$ participated at 24 months. We were however concerned that the relation between exposure and outcome may differ between responders and non-responders. As a result of the prospective design of the study we were able to examine the relation between baseline predictors and outcome at 12 months for those subjects who did and did not respond at 24 months. We were unable to examine this relation for monotonous work due to the small number of nonresponders at 24 months reporting monotonous work and new onset shoulder pain at baseline. However, for the remaining predictor variables there were no significant differences. 


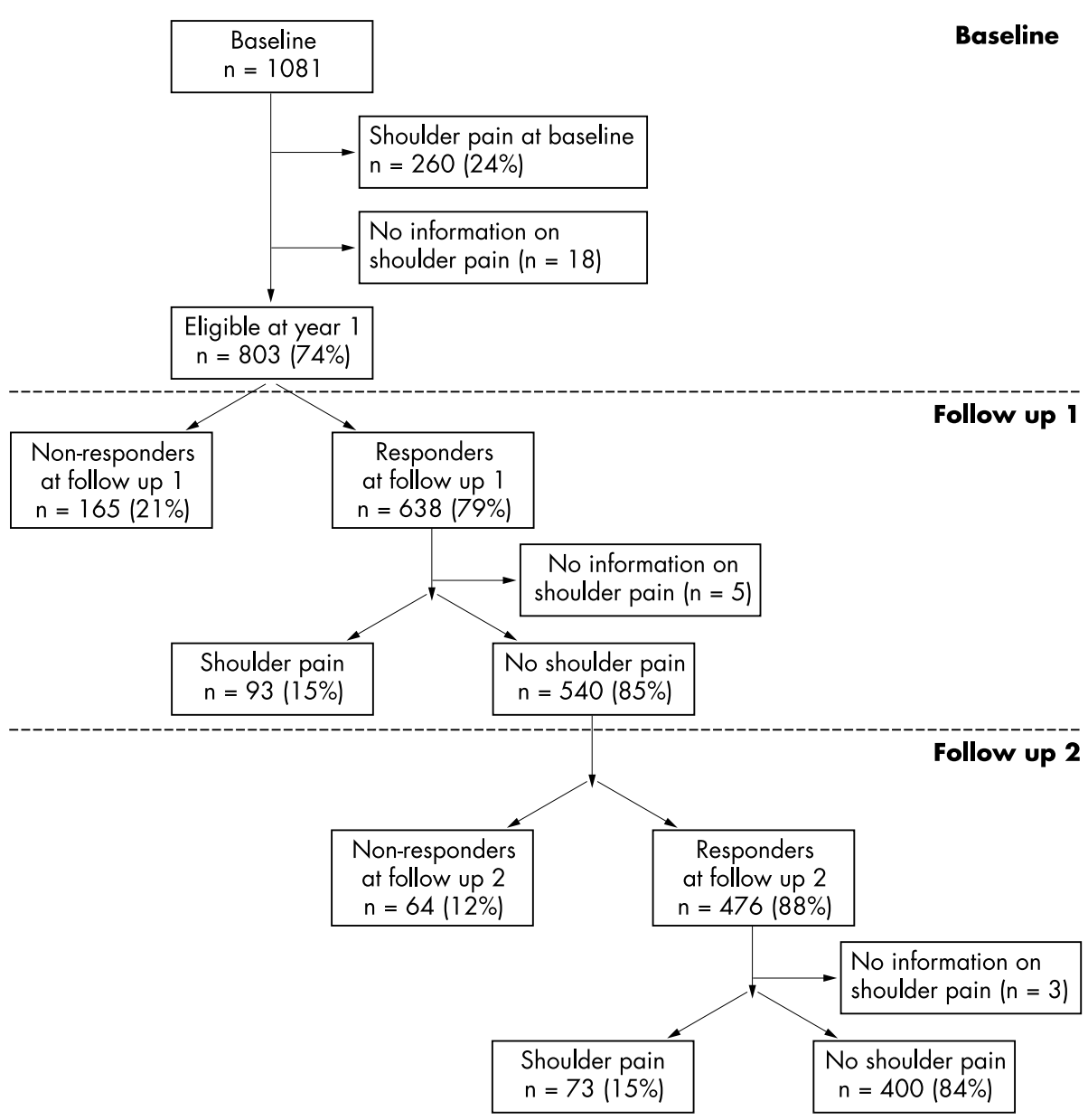

\section{DISCUSSION}

Results from previous studies of workplace mechanical and psychosocial factors have been equivocal. Much of the published work, by its cross sectional nature, may have overestimated some associations due to recall bias but, by contrast, under estimated some associations due to the healthy worker effect. In the present prospective study of newly employed workers we have found strong evidence to support the hypothesis that mechanical factors are important in the new onset of shoulder pain. ${ }^{13}$ In addition we have shown only a modest contribution of psychosocial factors, though perceived monotonous working conditions was an important predictor of shoulder pain.

There are several strengths in relation to the current study. First, it was conducted within a newly employed workforce to minimise the healthy worker effect. It is possible that the healthy worker effect may still have an influence, although our data indicate that this is unlikely. Only a small proportion of individuals changed their job ( $\mathrm{n}=59(9 \%)$ at 12 months; $\mathrm{n}=30(6 \%)$ at 24 months), and only one person reported that they had left their job due to aches or pains. Nevertheless, it is likely that those people applying for

\begin{tabular}{|c|c|c|c|c|c|}
\hline & \multirow[b]{2}{*}{$\begin{array}{l}\text { Eligible } \\
\text { (n) }\end{array}$} & \multicolumn{2}{|c|}{12 month follow up } & \multicolumn{2}{|c|}{24 month follow up } \\
\hline & & $\begin{array}{l}\text { Response rate } \\
\mathrm{n}(\%)\end{array}$ & $\begin{array}{l}\text { Prevalence rate } \\
\text { n (\%) }\end{array}$ & $\begin{array}{l}\text { Response rate } \\
\text { n (\%) }\end{array}$ & $\begin{array}{l}\text { Prevalence rate } \\
\text { n (\%) }\end{array}$ \\
\hline Firefighters & 118 & $104(88)$ & $16(16)$ & $78(90)$ & $12(16)$ \\
\hline Police officers & 36 & $30(83)$ & $4(13)$ & $22(85)$ & $3(14)$ \\
\hline Army officers & 54 & $36(67)$ & $4(11)$ & $29(91)$ & $2(7)$ \\
\hline Army infantry & 43 & $20(47)$ & $7(35)$ & $9(69)$ & 1 (11) \\
\hline Army clerks & 60 & $51(85)$ & $5(10)$ & $44(96)$ & $7(16)$ \\
\hline Dentists & 89 & 65 (73) & $8(12)$ & $55(96)$ & 7 (13) \\
\hline Podiatrists & 65 & 51 (78) & $11(22)$ & $35(92)$ & $8(23)$ \\
\hline Nurses & 72 & $58(81)$ & $6(11)$ & $47(92)$ & $6(13)$ \\
\hline Forestry workers & 29 & $21(72)$ & $2(10)$ & $15(79)$ & $2(13)$ \\
\hline Retail workers & 89 & 77 (87) & $16(21)$ & $50(83)$ & $4(8)$ \\
\hline Postal workers & 53 & $43(81)$ & $5(12)$ & $25(66)$ & $8(32)$ \\
\hline Shipbuilders & 95 & $82(86)$ & $9(11)$ & 67 (92) & $13(19)$ \\
\hline Total & 803 & $638(79)$ & $93(15)$ & $476(88)$ & $73(15)$ \\
\hline
\end{tabular}


Table 2 Work related mechanical risk factors and new onset shoulder pain* (univariate associations)

\begin{tabular}{|c|c|c|c|c|c|c|c|c|}
\hline \multirow[b]{3}{*}{ Exposure } & \multicolumn{4}{|c|}{ Shoulder pain } & & & & \\
\hline & \multicolumn{2}{|c|}{ Baseline } & \multicolumn{2}{|c|}{12 months } & \multicolumn{2}{|c|}{ Unadjusted } & \multicolumn{2}{|c|}{ Adjusted* } \\
\hline & No & Yes & No & Yes & OR & $95 \% \mathrm{Cl}$ & OR & $95 \% \mathrm{Cl}$ \\
\hline \multicolumn{9}{|c|}{$\begin{array}{l}\text { Manual handling activities } \\
\text { Lifting with one or two hands }\end{array}$} \\
\hline Never & 189 & 20 & 142 & 18 & 1 & Referent & 1 & Referent \\
\hline$\leqslant 22 \mathrm{lb}$ & 163 & 33 & 128 & 27 & 1.8 & 1.2 to 2.8 & 1.9 & 1.2 to 3.1 \\
\hline$>22 \mathrm{lb}$ & 179 & 37 & 1233 & 26 & 1.8 & 1.2 to 2.8 & 2.2 & 1.3 to 3.8 \\
\hline \multicolumn{9}{|c|}{ Carrying on one shoulder } \\
\hline Never & 441 & 63 & 315 & 56 & 1 & Referent & 1 & Referent \\
\hline$\leqslant 25 \mathrm{lb}$ & 48 & 11 & 42 & 10 & 1.5 & 0.9 to 2.5 & 1.5 & 0.9 to 2.6 \\
\hline$>25 \mathrm{lb}$ & 47 & 16 & 37 & 6 & 1.7 & $1.0-2.8$ & 1.8 & 0.99 to 3.4 \\
\hline \multicolumn{9}{|c|}{ Lifting at or above shoulder level } \\
\hline Never & 409 & 62 & 319 & 49 & 1 & Referent & 1 & Referent \\
\hline$\leqslant 20 \mathrm{lb}$ & 60 & 13 & 41 & 14 & 1.8 & 1.1 to .8 & 2.0 & 1.2 to 3.3 \\
\hline$>20 \mathrm{lb}$ & 63 & 17 & 35 & 9 & 1.7 & 1.1 to 2.8 & 2.2 & 1.2 to 3.9 \\
\hline \multicolumn{9}{|c|}{ Pushing/pulling } \\
\hline Never & 332 & 48 & 586 & 86 & 1 & Referent & 1 & Referent \\
\hline$<70 \mathrm{lb}$ & 98 & 16 & 180 & 30 & 1.1 & 0.7 to 1.8 & 1.3 & 0.8 to 2.2 \\
\hline$\geqslant 70 \mathrm{lb}$ & 105 & 27 & 162 & 47 & 2.0 & 1.3 to 2.9 & 2.6 & 1.6 to 4.2 \\
\hline \multicolumn{9}{|l|}{ Posture } \\
\hline \multicolumn{9}{|c|}{ Drive as part of job } \\
\hline No & 473 & 79 & 322 & 54 & 1 & Referent & 1 & Referent \\
\hline Yes & 66 & 14 & 73 & 18 & 1.4 & 0.9 to 2.1 & 1.5 & 0.9 to 2.5 \\
\hline \multicolumn{9}{|c|}{ Stretching below knee level } \\
\hline Never & 310 & 42 & 212 & 41 & 1 & Referent & 1 & Referent \\
\hline$<15 \min$ & 173 & 36 & 142 & 22 & 1.2 & 0.8 to 1.7 & 1.1 & 0.8 to 1.7 \\
\hline$\geqslant 15 \mathrm{~min}$ & 54 & 14 & 41 & 10 & 1.6 & 0.96 to 2.6 & 1.6 & 0.95 to 2.8 \\
\hline \multicolumn{9}{|c|}{$\begin{array}{l}\text { Working with hands above } \\
\text { shoulder }\end{array}$} \\
\hline Never & 315 & 46 & 213 & 35 & 1 & Referent & 1 & Referent \\
\hline$<15 \min$ & 125 & 18 & 126 & 23 & 1.1 & 0.7 to 1.6 & 1.1 & 0.7 to 1.7 \\
\hline$\geqslant 15 \mathrm{~min}$ & 94 & 28 & 57 & 15 & 1.9 & 1.2 to 2.8 & 1.9 & 1.2 to 2.9 \\
\hline \multicolumn{9}{|c|}{ Repetitive arm/wrist movements } \\
\hline Never & 119 & 15 & 107 & 23 & 1 & Referent & 1 & Referent \\
\hline$<2$ hours & 206 & 39 & 136 & 22 & 1.1 & 0.7 to 1.6 & 1.0 & 0.6 to 1.6 \\
\hline$\geqslant 2$ hours & 212 & 39 & 152 & 27 & 1.1 & 0.7 to 1.7 & 1.0 & 0.6 to 1.6 \\
\hline
\end{tabular}

particular types of jobs may have initially been healthier, a factor outside the control of observational studies.

Second, the current study was conducted as a prospective cohort study. Almost all previous studies examining work related risk factors for shoulder pain have been cross sectional. In a recent review ${ }^{2}$ of occupational risk factors for shoulder pain, only one of 29 studies was designed as a prospective cohort study; however, outcome was collected retrospectively and physical job demands were based on job title. ${ }^{14}$ A more recent prospective study has been conducted among workers of a forestry company and examined the relative contribution of work related, individual, and physical activity factors. However, this study was conducted within one company and the majority of workers (72\%) were blue collar workers (paper machine process and forest workers) from an established workforce. ${ }^{15}$ The study design we have adopted has the ability to disentangle the relation between baseline risk factors and subsequent new episodes of shoulder pain in newly employed workers.

When considering the results from the present study a number of methodological issues must be considered. First, in the present study work related exposures were measured by means of a validated self completion questionnaire. This questionnaire had previously been validated by comparing responses with simultaneous observations and was found to provide an accurate assessment of work related activities. ${ }^{7}$ The questionnaire was specifically designed to examine risk factors for shoulder pain; however, certain work related tasks specific to the shoulder may have been omitted. Yet the questionnaire covered the majority of items that have previously been found to be associated with shoulder pain. ${ }^{2}$ However, there may be some residual confounding due to other unmeasured exposures, for example, leisure time activities.

Previous studies have used job titles in order to estimate workload. ${ }^{16}{ }^{17}$ Clearly this is not ideal as job title gives a poor indication of the tasks involved as a part of one's job. In addition it gives no idea as to how often (frequency), how long (duration), or what effort (weight) individuals spend in performing certain work tasks. Others have measured exposures by using direct assessments (for example, using an observer); however, this is costly and time consuming..$^{18} 19$

Second, individuals were asked about manual handling activities and working conditions during the past working day and therefore work related exposures may not represent a typical working day. In an attempt to gauge this we asked individuals how physically demanding their work was compared to usual. The majority of individuals reported that it was about as physically demanding as usual (56\% and $67 \%$ at 12 and 24 months respectively); furthermore, these proportions did not differ according to whether individuals reported shoulder pain or not.

Third, a proportion of subjects did not respond at follow up. However, the overall response rate was high $(79 \%$ at 12 months and $88 \%$ at 24 months). Nevertheless, response rates in the current study varied according to occupational group. There is no reason to assume that the relation between these risk factors and shoulder pain would be any different between non-participants and participants. Due to the prospective study design we were able to examine baseline 
Table 3 Work related and individual psychosocial risk factors and new onset shoulder pain* (univariate associations)

\begin{tabular}{|c|c|c|c|c|c|c|c|c|}
\hline \multirow[b]{3}{*}{ Exposure } & \multicolumn{4}{|c|}{ Shoulder pain } & & & & \\
\hline & \multicolumn{2}{|c|}{ Baseline } & \multicolumn{2}{|c|}{12 months } & \multicolumn{2}{|c|}{ Unadjusted } & \multicolumn{2}{|c|}{ Adjusted* } \\
\hline & No & Yes & No & Yes & $\overline{O R}$ & $95 \% \mathrm{Cl}$ & $\overline{O R}$ & $95 \% \mathrm{Cl}$ \\
\hline \multicolumn{9}{|l|}{ Job demand } \\
\hline Never/occasionally & 414 & 75 & 329 & 62 & 1 & Referent & 1 & Referent \\
\hline At least half of the time & 117 & 18 & 68 & 11 & 0.9 & 0.6 to 1.3 & 0.9 & 0.6 to 1.4 \\
\hline \multicolumn{9}{|l|}{ Monotonous work } \\
\hline Never/occasionally & 475 & 74 & 336 & 57 & 1 & Referent & 1 & Referent \\
\hline At least half of the time & 55 & 19 & 57 & 15 & 1.9 & 1.2 to 2.9 & 1.9 & 1.2 to 3.1 \\
\hline \multicolumn{9}{|l|}{ Hectic work } \\
\hline Never/occasionally & 370 & 63 & 289 & 59 & 1 & Referent & 1 & Referent \\
\hline At least half of the time & 161 & 30 & 108 & 14 & 0.9 & 0.6 to 1.3 & 0.9 & 0.6 to 1.4 \\
\hline \multirow{2}{*}{\multicolumn{9}{|c|}{ Job satisfaction }} \\
\hline & & & & & & & & \\
\hline Not dissatisfied & 520 & 92 & 372 & 69 & 1 & Referent & 1 & Referent \\
\hline (Very)/dissatisfied & 11 & 1 & 21 & 3 & 0.7 & 0.2 to 2.0 & 0.7 & 0.2 to 2.1 \\
\hline \multicolumn{9}{|l|}{ Social support } \\
\hline \multicolumn{9}{|l|}{ Support from colleagues } \\
\hline Not dissatisfied & 523 & 92 & 381 & 69 & 1 & Referent & 1 & Referent \\
\hline (Very)/dissatisfied & 7 & 1 & 15 & 3 & 1.0 & 0.4 to 3.0 & 1.0 & 0.3 to 3.1 \\
\hline \multicolumn{9}{|l|}{ Control over work } \\
\hline \multicolumn{9}{|l|}{ Control over own work } \\
\hline At least sometimes & 482 & 83 & 376 & 68 & 1 & Referent & 1 & Referent \\
\hline (Very)/seldom & 46 & 9 & 21 & 4 & 1.1 & 0.6 to 2.0 & 1.0 & 0.5 to 2.0 \\
\hline \multicolumn{9}{|l|}{ Learn new things } \\
\hline At least sometimes & 511 & 90 & 375 & 67 & 1 & Referent & 1 & Referent \\
\hline (Very)/seldom & 21 & 3 & 22 & 6 & 1.2 & 0.6 to 2.5 & 1.0 & 0.5 to 2.3 \\
\hline \multicolumn{9}{|l|}{ Individual distress (GHQ) } \\
\hline \multicolumn{9}{|l|}{ GHQ total } \\
\hline 0 & 301 & 52 & 256 & 53 & 1 & Referent & 1 & Referent \\
\hline 1 & 97 & 14 & 49 & 5 & 0.7 & 0.4 to 1.2 & 0.7 & 0.4 to 1.2 \\
\hline $2-3$ & 78 & 12 & 43 & 7 & 0.8 & 0.5 to 1.4 & 0.9 & 0.5 to 1.5 \\
\hline$\geqslant 3$ & 62 & 15 & 50 & 8 & 1.1 & 0.7 to 1.8 & 1.1 & 0.7 to 1.9 \\
\hline
\end{tabular}

predictors of shoulder pain at 12 months for those participating and not participating at 24 months. We found that the relations did not differ.

Fourth, pain status was measured at three time points (baseline, 12 and 24 months) and no attempt was made to ascertain new cases in the intervening months. In order to minimise recall bias subjects were asked about their pain experiences during the past month. Therefore we are unable to say anything about the new onset prevalence rate during this time. Nevertheless this does not affect the internal comparisons between predictors and outcomes in our study.

In the current study the prevalence of new onset shoulder pain was high among newly employed workers. Musculoskeletal pain is very common, with many episodes being well established in childhood or adolescence. ${ }^{20}$ The recurrent nature of such pain syndromes means that individuals will move in and out of state, therefore the majority of episodes will be recurring episodes rather than

Table 4 Work conditions and other pain as risk factors for new onset shoulder pain* (univariate associations)

\begin{tabular}{|c|c|c|c|c|c|c|c|c|}
\hline \multirow[b]{3}{*}{ Exposure } & \multicolumn{4}{|c|}{ Shoulder pain } & \multirow{2}{*}{\multicolumn{2}{|c|}{ Unadjusted }} & \multirow{2}{*}{\multicolumn{2}{|c|}{ Adjusted* }} \\
\hline & \multicolumn{2}{|c|}{ Baseline } & \multicolumn{2}{|c|}{12 months } & & & & \\
\hline & No & Yes & No & Yes & OR & $95 \% \mathrm{Cl}$ & OR & $95 \% \mathrm{Cl}$ \\
\hline \multicolumn{9}{|c|}{$\begin{array}{l}\text { Working conditions } \\
\text { Work in hot conditions }\end{array}$} \\
\hline No & 396 & 71 & 304 & 59 & 1 & Referent & 1 & Referent \\
\hline Yes & 142 & 21 & 87 & 13 & 0.8 & 0.5 to 1.2 & 0.8 & 0.5 to 1.2 \\
\hline \multicolumn{9}{|c|}{ Work in cold conditions } \\
\hline No & 432 & 71 & 329 & 63 & 1 & Referent & 1 & Referent \\
\hline Yes & 83 & 21 & 60 & 9 & 1.2 & 0.8 to 1.8 & 1.1 & 0.7 to 1.9 \\
\hline \multicolumn{9}{|c|}{ Work in damp conditions } \\
\hline No & 399 & 66 & 308 & 55 & 1 & Referent & 1 & Referent \\
\hline Yes & 94 & 19 & 81 & 17 & 1.2 & 0.8 to 1.8 & 1.2 & 0.7 to 2.0 \\
\hline \multicolumn{9}{|c|}{$\begin{array}{l}\text { Other pain } \\
\text { (Any pain other than shoulder pain) }\end{array}$} \\
\hline No & 315 & 46 & 228 & 32 & 1 & Referent & 1 & Referent \\
\hline Yes & 225 & 47 & 172 & 41 & 1.5 & 1.1 to 2.1 & 1.6 & 1.1 to 2.2 \\
\hline
\end{tabular}


Table 5 Final model predictors for new onset shoulder pain* (multivariate associations)

\begin{tabular}{|c|c|c|}
\hline Exposure & OR & $95 \% \mathrm{Cl}$ \\
\hline \multicolumn{3}{|l|}{ Mechanical load } \\
\hline \multicolumn{3}{|c|}{ Liffing with one or two hands } \\
\hline Never & 1 & Referent \\
\hline$\leqslant 22 \mathrm{lb}$ & 1.6 & 0.99 to 2.7 \\
\hline$>22 \mathrm{lb}$ & 1.7 & 0.9 to 3.0 \\
\hline \multicolumn{3}{|l|}{ Pushing/pulling } \\
\hline Never & 1 & Referent \\
\hline$>70 \mathrm{lb}$ & 1.1 & 0.7 to 1.9 \\
\hline$\geqslant 70 \mathrm{lb}$ & 1.9 & 1.1 to 3.3 \\
\hline \multicolumn{3}{|l|}{ Posture } \\
\hline \multicolumn{3}{|c|}{ Working with hands above shoulder } \\
\hline Never & 1 & Referent \\
\hline$<15 \min$ & 1.0 & 0.6 to 1.6 \\
\hline$\geqslant 15 \mathrm{~min}$ & 1.6 & 0.98 to 2.5 \\
\hline \multicolumn{3}{|l|}{ Psychosocial } \\
\hline \multicolumn{3}{|l|}{ Monotonous work } \\
\hline Never/occasionally & 1 & Referent \\
\hline At least half of the time & 1.7 & 1.1 to 2.8 \\
\hline \multirow{2}{*}{\multicolumn{3}{|c|}{ Other pain }} \\
\hline & & \\
\hline No & 1 & Referent \\
\hline Yes & 1.3 & 0.9 to 1.9 \\
\hline
\end{tabular}

incident cases. Consequently it makes sense to establish which risk factors are important in the new onset of musculoskeletal disorders so that suitable preventative measures can be undertaken.

New onset prevalence rates of shoulder pain varied largely according to occupational group. However, rather than identify risk markers by using job titles we were interested in identifying specific risk factors: specific occupational mechanical, psychosocial, and environmental factors for shoulder pain. Although the workplace is a convenient place for measuring these factors they are not exclusive, and other factors outside the workplace may be equally important. ${ }^{21}$ The highest new onset prevalence rate of shoulder pain occurred at baseline. However, the fact that subjects, initially free from shoulder pain at baseline, commonly developed new onset shoulder pain at follow up may indicate the importance of these factors.

Results from the cross sectional phase of this study on regional pain symptoms have recently been published. ${ }^{62}$ Many of the manual handling activities were found to be associated with shoulder pain. ${ }^{6}$ Among the work related psychosocial factors, stressful and hectic work always or most of the time were found to be significantly associated with shoulder pain; in addition higher levels of individual psychological distress on the GHQ were also associated with shoulder pain. ${ }^{22}$ However, due to the cross sectional design the relation between these factors and shoulder pain was unclear; for example, we could not conclude that shoulder pain was a consequence of stressful work or whether individuals found their work more stressful as a result of their shoulder pain. By taking advantage of the prospective design we were able to disentangle the temporal relation for these factors.

The pathological basis of most cases of shoulder pain is poorly understood. Although such pain can often be attributed to a specific diagnosis, ${ }^{23}$ this is not the case for a significant proportion. ${ }^{24}$ It would be of interest to determine to what extent risk factors are common across specific and non-specific disorders. However, in our study, we found that only a small proportion of those subjects who underwent a physical examination were diagnosed with a specific shoulder disorder (13\%), and therefore precluded the consideration of that. However, this remains a challenge for the future. Thus consideration of a potential role of psychosocial factors in increasing susceptibility to symptom onset is important. Psychosocial factors may operate through a different mechanism to that of work related mechanical factors. A number of mechanisms through which psychosocial factors may influence new onset musculoskeletal pain have been hypothesised..$^{25}$ For example, by directly influencing loading on the spine or through chemical reactions that occur while performing certain tasks as a result of increased muscle tension. Other hypotheses include a reduced pain threshold as a result of stressors at work, or avoidance of potential stressors at work. ${ }^{25}$ Whether the influence of such psychosocial factors is a short or long term effect is currently subject to debate. ${ }^{26}$ We found over a relatively short period that the majority of psychosocial risk factors did not predict new onset shoulder pain. However, we have shown that subjects who perceive their work to be monotonous or boring are at an increased risk of developing new shoulder pain, and this risk is independent of other work related factors. In our previous work we have found monotonous work to be independently associated with an increased risk of shoulder pain and disability in the general population, ${ }^{27}$ and with the new onset of forearm pain..$^{28}$ Monotonous work may be an indicator for repetitive tasks within the workplace. However, each of these studies examined the associations with both mechanical and psychosocial factors, by including questions on repetitive movements of the wrists or arms and a separate question on whether individuals found their work was boring, monotonous, or repetitive. We found the latter to be independently associated with pain outcome.

What therefore are the implications of the present findings? Ergonomic interventions and rehabilitation programmes for the prevention of musculoskeletal disorders are currently in their infancy and few studies have been published..$^{29}$ For example, a rehabilitation programme comprising physical training, information, education, social interaction, and workplace visits, for individuals with neck and shoulder disorders was found to be no better than usual treatment of physiotherapy, medication, rest, and sick leave. ${ }^{31}$ In many occupations mechanical load bearing is unavoidable, whereas interventions aimed at the psychosocial environment may be less difficult to implement. For example, alleviating the perception of monotonous or tedious work could perhaps be achieved through more interesting and varied work tasks with an increased number of breaks, better job opportunities, ${ }^{32}$ or improved communication between employers and employees.

\section{APPENDIX: SOURCES OF RECRUITMENT}

- Newly opened workplaces in the northwest of England that required a new workforce. Firstly, a recently opened supermarket included employees from a number of areas including checkouts, shelf stacking, service counters, a crèche, general office, and stock management staff. Secondly, workers from a postal distribution centre responsible for unloading and loading trolleys of mailbags on and off trains and lorries; other workers were employed in administration or catering.

- Services or organisations which frequently recruit groups of trainees. A total of nine intakes of full time paid firefighters, from four local counties, in their period of initial training. All police force trainees from three intakes of one police force were invited to participate. New army recruits included officers, infantry, and clerks. Officers from three companies were selected at random, as were infantry soldiers from two battalions and all clerks enrolled on three training intakes were included. 
- Apprentices, carrying out construction and engineering tasks, from an established shipbuilding company were invited to participate.

- Individuals at the end of vocational courses who were training for specific careers were also recruited. This group included nursing students from one academic institution, dentistry students from two academic institutions, all podiatry students from a further two academic institutions, and forestry students at a specialised college.

\section{ACKNOWLEDGEMENTS}

This study was funded by the British Occupational Health Research Foundation and the Arthritis Research Campaign, Chesterfield, UK. We would like to thank the individuals who permitted us access to their workforce and to all the workers who participated in the study. We would also like to thank Professor Nicola Cherry who was involved in aspects of study design and conduct, and Christina Pritchard and Stewart Taylor who were involved in the data collection.

\section{Authors' affiliations}

E F Harkness, E S Nahit, A J Silman, J McBeth, Arthritis Research Campaign Epidemiology Unit, Medical School, University of Manchester, Oxford Road, Manchester M13 9PT, UK

G J Macfarlane, Unit of Chronic Disease Epidemiology, Medical School, University of Manchester, Oxford Road, Manchester M13 9PT, UK

\section{REFERENCES}

1 NIOSH. Musculoskeletal disorders and workplace factors: a critical review of epidemiologic evidence for work-related musculoskeletal disorders of the neck, upper extremity and low back. Cincinatti: DHHS (NIOSH), 1997.

2 van der Windt DA, Thomas E, Pope DP, et al. Occupational risk factors for shoulder pain: a systematic review. Occup Environ Med 2000:57:433-42.

3 van der Windt DA, Croft PR. Shoulder pain. In: Crombie IK, Croft PR, Linton SJ, et al, eds. Epidemiology of pain: a report of the Task Force on Epidemiology of the International Association for the Study of Pain. Seattle: IASP Press, 1999:257-81.

4 Karasek RA. Job demands, job decision latitude and mental strain: implications for job redesign. Administrative Science Quarterly 1979;24:285-311.

5 Bongers PM, de Winter CR, Kompier MA, et al. Psychosocial factors at work and musculoskeletal disease. Scand J Work Environ Health 1993; 19:297-312.

6 Nahit ES, Macfarlane GJ, Pritchard CM, et al. Short term influence of mechanical factors on regional musculoskeletal pain: a study of new workers from 12 occupational groups. Occup Environ Med 2001;58:374-81.

7 Pope DP, Silman AJ, Cherry NM, et al. Validity of a self-completed questionnaire measuring the physical demands of work. Scand J Work Environ Health 1998;24:376-85.

8 Papageorgiou AC, Macfarlane GJ, Thomas E, et al. Psychosocial factors in the workplace-do they predict new episodes of low back pain? Evidence from the South Manchester Back Pain Study. Spine 1997;22:1137-42.
9 Leino PI, Hanninen V. Psychosocial factors at work in relation to back and limb disorders. Scand J Work Environ Health 1995;21:134-42.

10 Macfarlane GJ, Hunt IM, Silman AJ. Role of mechanical and psychosocial factors in the onset of forearm pain: prospective population based study. BMJ 2000;321:676-9.

11 Goldberg DP, Williams P. A user's guide to the General Health Questionnaire. Windsor: Nfer-Nelson, 1998.

12 Liang K-Y, Zeger SL. Longitudinal data analysis using generalised linear models. Biometrika 1986;73:13-22.

13 Stata Statistical Software. Stata, release 7.0. TX: State Corporation, 2001.

14 Bergenudd $\mathbf{H}$, Lindgarde F, Nilsson B, et al. Shoulder pain in middle age. A study of prevalence and relation to occupational work load and psychosocial factors. Clin Orthop 1988:234-8.

15 Miranda H, Viikari-Juntura E, Martikainen R, et al. A prospective study of work related factors and physical exercise as predictors of shoulder pain. Occup Environ Med 2001;58:528-34.

16 Hagberg $M$, Wegman DH. Prevalence rates and odds ratios of shoulderneck diseases in different occupational groups. Br J Ind Med 1987:44:602-10.

17 Kivi P. Rheumatic disorders of the upper limbs associated with repetitive occupational tasks in Finland in 1975-1979. Scand J Rheumatol 1984;13:101-7.

18 Burdorf A, van Riel M, Brand T. Physical load as risk factor for musculoskeletal complaints among tank terminal workers. Am Ind Hyg Assoc J 1997;58:489-97.

19 Winkel J, Westgaard R. Occupational and individual risk factors for shoulderneck complaints: Part II-The scientific basis (literature review) for the guide. Int J Ind Ergon 1992;10:85-104.

20 Vikat A, Rimpela M, Salminen JJ, et al. Neck or shoulder pain and low back pain in Finnish adolescents. Scand J Public Health 2000;28:164-73.

21 Papageorgiou AC, Croft PR, Thomas E, et al. Psychosocial risks for low back pain: are these related to work? Ann Rheum Dis 1998;57:500-2

22 Nahit ES, Pritchard CM, Cherry NM, et al. The influence of work related psychosocial factors and psychological distress on regional musculoskeletal pain: a study of newly employed workers. J Rheumatol 2001;28:1378-84.

23 Cooper C, Baker PD. Upper limb disorders. Occup Med (Lond) 1996;46:435-7.

24 Bjelle A. Epidemiology of shoulder problems. Baillieres Clin Rheumatol 1989:3:437-51.

25 Davis KG, Heaney CA. The relationship between psychosocial work characteristics and low back pain: underlying methodological issues. Clin Biomech 2000;15:389-406.

26 Hoogendoorn WE, Bongers PM, de Vet HC, et al. Comparison of two different approaches for the analysis of data from a prospective cohort study: an application to work related risk factors for low back pain. Occup Environ Med 2002;59:459-65.

27 Pope DP, Croft PR, Pritchard CM, et al. Occupational factors related to shoulder pain and disability. Occup Environ Med 1997;54:316-21.

28 Taylor S, Nahit ES, Papageorgiou A, et al. Predicting the onset of forearm pain: a prospective study in the workplace. Rheumatology 2002;40:73-4.

29 Waddell G, Burton AK. Occupational health guidelines for the management of low back pain at work: evidence review. Occup Med (Lond) 2001;51:124-35

30 Burton AK, Symonds TL, Zinzen E, et al. Is ergonomic intervention alone sufficient to limit musculoskeletal problems in nurses? Occup Med (Lond) 1997; 47:25-32.

31 Ekberg K, Bjorkqvist B, Malm P, et al. Controlled two year follow up of rehabilitation for disorders in the neck and shoulders. Occup Environ Med 1994;51:833-8.

32 Bongers PM. The cost of shoulder pain at work. BMJ 2001;322:64-5. 